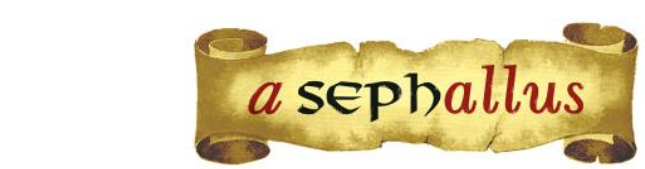

Revista aSEPHallus de Orientação Lacaniana

Núcleo Sephora de Pesquisa sobre o Moderno e o Contemporâneo

ISSN $1809-709 \mathrm{X}$

\title{
A psicanálise na instituição de saúde mental
}

Gabriela Rinaldi Meyer

Psicanalista

Mestre em Teoria Psicanalítica pela Universidade Federal do Rio de Janeiro / UFRJ (Rio de Janeiro, Brasil) Doutora em Psicologia Clínica pela Universidade de São Paulo / USP (São Paulo, Brasil) Pós-Doutora em Psicologia Clínica pela Pontifícia Universidade Católica de São Paulo /PUC-SP Professora do curso de Especialização em Teoria Psicanalítica e prática Clínico- Institucional da Universidade Veiga de Almeida / UVA (Rio de Janeiro, Brasil)

Supervisora Clínica e Institucional do CAPSI João de Barro (Rio de Janeiro, Brasil). E-mail: gabriela.rinaldi@gmail.com

Resumo: O presente artigo pretende discutir os impasses e conflitos que surgem no encontro da psicanálise com a instituição de saúde mental com o objetivo de construir uma relação possível à ambas. Partindo do princípio de que a psicanálise surgiu como um novo campo de saber, teórico e clínico no contexto da clínica privada- definida como uma prática cuja função é escutar a fala do sujeito em sua singularidade - como pensar sua inserção em um dispositivo institucional? Pensar a psicanálise na instituição significa pensá-la em relação a outros campos de saber e isso tem implicações diretas sobre a clínica que irá se desenvolver. De que forma incluir o discurso analítico como ferramenta útil à clínica que se desenvolve numa instituição de saúde mental? É possível conceber a psicanálise como mais um dispositivo disciplinar?

Palavras-chave: psicanálise; sujeito; saúde mental; instituição.

\section{La psychanalyse dans l'institution de la santé mentale}

Cet article traite des impasses et des conflits qui se posent dans la rencontre de la psychanalyse avec l'institution de la santé mentale afin de construire une relation possible aux deux à la fois. Supposant que la psychanalyse a émergé comme un nouveau champ de connaissances, théorique et clinique dans le contexte de la pratique privée- définie comme une pratique clinique dont la fonction est d'écouter le discours du sujet dans sa singularité- comment penser leur inclusion dans un dispositif institutionnel? Pensez la psychanalyse dans l'institution signifie y penser par rapport aux autres domaines de la connaissance, ce qui a des implications directes sur la clinique qui va se développer. Comment inclure le discours analytique comme un outil clinique utile à un établissement de santé mentale? Il est possible de concevoir la psychanalyse comme un autre dispositif disciplinaire?

Mots-clés: psychanalyse; sujet; santé mental; instituition.

\section{Psychoanalysis in the mental health institution}

This article discusses the impasses and conflicts that arise from the meeting of psychoanalysis with the mental health institution, in order to build a possible relationship for both. Assuming that psychoanalysis has emerged as a new field of knowledge, theoretical and clinical in the context of private clinical practice - defined as a clinical practice whose function is to listen to the speech of the subject in its uniqueness- how can we imagine its inclusion in an institutional setting? Reflecting on the psychoanalysis in the mental health institution means to analyze it in relation to other fields of knowledge, and this has direct implications on the clinical practice that will be developed. How to include the analytical discourse as an useful tool to the clinical practice developed in a mental health institution? Is it possible to think of it as just another disciplinary tool?

Key-words: psychoanalysis; subject; mental health; institution. 


\title{
A psicanálise na instituição de saúde mental
}

\author{
Gabriela Rinaldi Meyer
}

\section{Introdução}

Não é recente a presença da psicanálise nas instituições de saúde mental pública, nas quais o trabalho do psicanalista torna-se ainda mais importante na clínica da psicose, uma vez que estas instituições, desde que transformadas, têm também um papel fundamental de abrigo e acolhimento de casos muito graves e intensos de sofrimento psíquico. Neste artigo pretendemos discutir os impasses e conflitos que surgem do encontro da psicanálise com a instituição, com o objetivo de construir uma relação possível entre ambas.

O principal impasse gira em torno do fato de que Freud funda a psicanálise a partir da clínica, mais especificamente dos atendimentos às histéricas, tendo o consultório particular como seu principal local de trabalho. Partindo do princípio de que a psicanálise surgiu como um novo campo de saber, teórico e clínico, no contexto da clínica privada, definindo-se como uma prática clínica que tem como função escutar a fala do sujeito em sua singularidade, como pensar sua inserção em um dispositivo institucional?

Pensar a psicanálise na instituição significa pensá-la em relação a outros campos de saber. Isso tem implicações diretas sobre a clínica que irá se desenvolver. Neste sentido, torna-se necessário especificar seus princípios, o que nos remete ao que Lacan (1987) define como a ética da psicanálise, uma ética do desejo que está referida ao real. Deste modo, trata-se de uma ética que não se enquadra em uma lógica idealista e humanitária e que também não caracteriza uma especialidade ou uma ética profissional, tal como a ética médica ou a ética da psicologia. A psicanálise não se enquadra na formação disciplinar que caracteriza a ciência contemporânea, a qual encontra-se dividida em especialidades. Desta forma, em sua ética, a psicanálise interdita a especialidade, pois refere-se a um saber do qual não se tem conhecimento, um saber não sabido, inconsciente, que toma o sujeito como a referência do próprio trabalho. Um saber que deve ser apontado pelo sujeito a partir de sua fala, sendo ela que dá a direção do trabalho.

O campo da saúde mental nasceu do movimento da Reforma Psiquiátrica. Quando inserida neste campo, a psicanálise ganha um lugar junto a outros saberes, ajudando a compor uma instituição transformada, marcada pela quebra da hegemonia médica e pela introdução da multidisciplinaridade. Neste sentido, localizamos um conflito que diz respeito ao fato de, na instituição, a psicanálise operar como mais uma especialidade junto as outras especialidades/disciplinas, ao mesmo tempo em que escapa deste lugar "especialista", justamente por ser constituída por uma ética da diferença, da singularidade.

O que especifica a psicanálise é, como dito, sua ética - a psicanálise na instituição diferenciase e afirma-se pela sustentação de um lugar de escuta do sujeito do inconsciente, posição pela qual ele é responsável (Lacan, 1998). Ela se defronta aí com um problema rotineiro e constante: a 
dificuldade dos profissionais que atuam no campo da saúde mental de escutar este sujeito.

O problema tratado nesse artigo pode ser resumido pela seguinte questão: de que forma incluir o discurso analítico como útil à clínica que se desenvolve numa instituição, lembrando que não se trata de uma instituição psicanalítica, mas sim de uma instituição de saúde mental? Que lugar para a psicanálise nesse contexto?

\section{O campo da saúde mental e a psicanálise}

Neste ponto, consideramos importante apresentar, mesmo que de forma sucinta, o trajeto da Reforma Psiquiátrica no Brasil, localizando, mais precisamente, o lugar que a psicanálise ganha nesse cenário a partir do surgimento do campo da saúde mental.

A Reforma Psiquiátrica no Brasil teve início no final da década de 1970, a partir do movimento constituído pelas denúncias, reivindicações e críticas aos maus tratos, descaso e violência do tratamento na saúde mental preponderante até então. Ao se caracterizar como um movimento de crítica ao paradigma médico e à sua hegemonia no tratamento da chamada "doença mental", a reforma propicia o surgimento do campo da saúde mental e, neste sentido, inaugura um novo espaço, multidisciplinar, que abre portas para a contribuição de diversos saberes à clínica que aí se institui. Neste novo contexto em que surgem novas formas de atendimento a uma população há muito excluída de qualquer possibilidade de tratamento, a psicanálise ganha espaço como um saber importante para a reformulação da prática, na medida em que propõe uma clínica do sujeito.

No contexto da reforma psiquiátrica, a noção de sujeito apresenta-se atravessada pela noção de cidadania, no que se convencionou chamar de "clínica ampliada" (Ministério da Saúde, 2009) preocupada com a reabilitação psicossocial. A psicanálise introduz uma outra dimensão da clínica, que diz respeito ao sujeito, não como sujeito da razão e da vontade, mas como sujeito do inconsciente. $\mathrm{Na}$ instituição de saúde mental caminham, portanto, lado a lado, duas noções diferentes de clínica: uma, que inclui a ideia de reabilitação psicossocial, tendo como referência central a questão da cidadania, e outra, a clínica psicanalítica, que valoriza prioritariamente o sujeito do inconsciente, implicando-o em suas escolhas e em sua forma de inserção no mundo. Podemos pensar que estas duas concepções clínicas compõem a clínica da atenção psicossocial, estando na base dos serviços de atendimento que surgem como substitutivos ao hospital psiquiátrico, os CAPS, CAPSi e CAPSad.

Ao nos determos no que diz respeito à clínica e, principalmente à clínica do sujeito, estamos trazendo à tona a discussão sobre a contribuição que a psicanálise pode oferecer para a construção de uma nova forma de atendimento aos psicóticos no contexto institucional, caminhando no sentido de valorizar a sua palavra, sua produção, a produção delirante, pois é a partir disso que se pode fazer advir a sua condição de sujeito. Foi Freud (1911/1996) quem nos apresentou a ideia de que o delírio dever ser valorizado como uma produção do sujeito na psicose e, portanto, não deve ser suprimido ou eliminado. Esta nova maneira de conceber o delírio pode ser tomada como um grande 
passo em direção ao aprofundamento da pesquisa sobre as psicoses. Ao contrário da clínica psiquiátrica, nosológica, que visa definir um diagnóstico, para logo em seguida suprimir o delírio na tentativa de cura do paciente, a psicanálise inaugura uma outra forma de tratar a questão. Entretanto, não podemos excluir a dimensão do sujeito como indivíduo e cidadão, já que estamos lidando o tempo todo com ele na instituição. A pergunta que surge, então, é: como conciliar estas duas dimensões? Como escutar o sujeito e implicá-lo em seu modo próprio de inserção no mundo, levando em conta as suas possibilidades de fazer laço social? Como tratar sem deixar de cuidar destas pessoas? Como cuidar sem cair na armadilha de fechar as portas para a expressão do sujeito do inconsciente?

A referência à noção de sujeito formulada pela psicanálise pressupõe a consideração de uma responsabilidade inconsciente por suas escolhas, mesmo nos casos mais graves de psicose. A referência a esta noção é fundamental para o desenvolvimento da clínica da psicose, especialmente na instituição de saúde mental, na medida em que ela supõe alguém em condições bem diferentes daquelas consideradas pela hegemonia médica, que coloca o sujeito no lugar de objeto portador de uma doença. Neste ponto, cabe esclarecer que desenvolver a clínica da psicose implica apostar na estrutura, mesmo que ela não se evidencie à maneira da neurose, na qual o sujeito comparece apagado como efeito do recalque, no intervalo entre dois significantes da cadeia associativa. Como será desenvolvido adiante, na psicose o sujeito se apresenta como objeto do gozo do Outro e isso é consequência da foraclusão do Nome-do-Pai, que barra o Outro (Lacan, 1985).

A clínica da atenção psicossocial, por estar referida ao campo da saúde mental, comporta as duas dimensões clínicas tratadas acima, tendo o sujeito como referência. A escuta da singularidade marca a prática analítica, garantindo a transmissão do discurso psicanalítico. É isso o que operacionaliza o discurso analítico no espaço particular e no público.

No contexto da psicanálise na instituição, consideramos frutífera a contribuição de Zenoni (2000) quando apresenta uma nova forma de conceber as relações entre a psicanálise e a instituição de saúde mental. $\mathrm{O}$ autor parte do princípio de que pensar tal relação não significa reduzi-la à transposição da psicanálise ligada ao tratamento das neuroses para a instituição. Não podemos simplesmente encaixá-la em um novo setting, o que seria transportar o consultório do psicanalista para o interior da instituição de saúde mental, colocando-a no lugar de envoltório do consultório do psicanalista. Pensar a instituição desse modo é ignorar a razão da sua existência e a natureza da clínica que ela acolhe. Em suas palavras:

Quando discutimos para saber quando a instituição é compatível com o consultório do analista ou não, desconhecemos a razão da existência da instituição, porque antes de existir para eventualmente tratar do sujeito, a instituição existe para acolhê-lo, colocá-lo ao abrigo, colocá-lo à distância, assisti-lo. Antes de ter um 
objetivo terapêutico, a instituição é uma necessidade social, uma resposta social a fenômenos clínicos. (Zenoni, 2000, p. 14)

Trata-se de reconhecer a diferença entre duas práticas: a do tratamento psicanalítico e a da instituição. Assim, podemos lidar com a diferença e construir, a cada caso, uma relação que potencialize o trabalho clínico. A questão não é saber se a psicanálise pode ser praticada na instituição, mas sim, pensar como o discurso analítico pode ser útil à clínica institucional, orientando o tratamento. $O$ analista não deve se excluir ou reivindicar um estatuto especial na instituição, pois seu desejo não se limita à cura. O desejo do analista é o de fazer operar a psicanálise, o discurso inconsciente. A questão aí volta-se precisamente para a transmissão da psicanálise. Não é a psicanálise que serve à instituição, mas ao contrário, é a instituição que deve servir à psicanálise, fazendo operar o discurso analítico pela transferência. Nas palavras de Zenoni: "A questão não é de saber qual psicanálise praticar na instituição, mas qual instituição praticar na psicanálise. (...) Colocar o problema nesses termos supõe reconhecer a motivação clínica da instituição" (Zenoni, 2000, p. 16).

O psicanalista faz parte de uma equipe multidisciplinar formada por vários profissionais do campo da saúde, equipe necessária para absorver nos CAPS, CAPSis e CAPSad, os atendimentos dos casos de psicoses, de autismo, as neuroses graves e os casos de alcoolismo e drogadição. Ao refletirmos sobre a especificidade de uma equipe multidisciplinar, condição sine qua non para que o trabalho com essa população seja possível, surge a questão: qual é o lugar do psicanalista nesta equipe? Atualmente ele está muito mais presente na instituição de saúde mental do que no passado, quando seu trabalho se restringia mais especificamente ao setting do consultório particular, o locus tradicional do qual se originou. A inserção do psicanalista aí traz algumas questões e dificuldades, pois o contexto institucional convoca-o a atuar num campo que o coloca em um lugar diferente, fugindo, muitas vezes, das regras básicas do dispositivo analítico instituído por Freud. A própria especificidade da estrutura da psicose convoca o psicanalista a ampliar o sentido stricto senso da clínica psicanalítica, através da utilização de outros dispositivos. Na instituição, o psicanalista é chamado a atender o sujeito, escutá-lo, não só no âmbito individual, mas também no âmbito grupal.

Neste ponto, podemos introduzir a concepção de "secretário do alienado" tal como Lacan a introduziu no Seminário 3(1955-1956/1985) sobre as psicoses. O psicanalista se coloca em um lugar de secretariar o sujeito, acompanhando-o em suas andanças, na construção de algum sentido para sua existência. Cabe dizer que o ato de secretariar diz respeito ao lugar do psicanalista na clínica da psicose, seja no consultório particular, seja na instituição. Na instituição, no entanto, isso se amplia e se diversifica. Deste modo, "atender" o paciente não significa somente se fechar numa sala e convidá-lo a falar de seus problemas, mas também acompanhá-lo numa oficina terapêutica, numa saída pelas redondezas ou simplesmente ajudá-lo a contar para seu médico o que está sentindo. De fato, tais diferenças inauguram um novo campo clínico que nos faz pensar em ampliar ou expandir 
a clínica psicanalítica, assim como Freud sugeriu em "Linhas de progresso na terapia psicanalítica" (1918) quando se refere a importância da inserção da psicanálise na assistência pública, o que implica uma adaptação da técnica psicanalítica, como deixa claro:

Defrontar-nos-emos, então, com a tarefa de adaptar a nossa técnica às novas condições. Não tenho dúvidas de que a validade de nossas hipóteses psicológicas causará boa impressão também sobre as pessoas pouco instruídas, mas precisaremos buscar as formas mais simples e mais facilmente inteligíveis de expressar as nossas doutrinas teóricas. (Freud, 1918/ 1996, p. 181)

Como dito na abertura desse artigo, o trabalho do psicanalista na instituição pública tornase ainda mais importante na clínica da psicose. Como psicanalista que tem desenvolvido um trabalho na instituição, estamos permanentemente a refletir sobre os ganhos que este trabalho clínico pode trazer não apenas para o tratamento da psicose, mas para a própria psicanálise. O psicanalista, ao acompanhar o paciente em suas caminhadas, ao escutar o delírio, abre espaço para a expressão do sujeito. A psicanálise inaugura uma nova forma de pensar a clínica da psicose, ancorada na valorização do que o sujeito endereça ao psicanalista por meio de sua fala na relação transferencial. A clínica psicanalítica se oferece, assim, como um lugar onde o psicótico pode construir e elaborar um sentido para suas formações delirantes.

Originalmente inaugurada por Freud, a clínica psicanalítica surgiu direcionada ao trabalho com a neurose. Freud não tratou da psicose, muito embora tenha se referido a ela em diversos trabalhos, mantendo, ao longo de sua obra um persistente interesse em refletir sobre os seus mecanismos. Dentre os vários textos que escreveu sobre o tema, um dos mais importantes é "Notas psicanalíticas sobre um Relato autobiográfico de um Caso de Paranoia - caso Schreber" (1911), que contém sua análise do livro Memórias de um doente dos nervos, de Daniel-Paul Schreber. É onde se encontra a principal contribuição freudiana para o estudo das psicoses.

As concepções da psiquiatria abordavam o delírio como um sintoma patológico. Como mencionado acima, Freud rompeu com essas concepções introduzindo uma novidade. Caracterizou o delírio como uma tentativa de restabelecimento de sentido. Ao apresentar esta nova via, a psicanálise abre espaço para o sujeito para além do sintoma patológico, incluindo o delírio como sua produção, como sua verdade. Esta nova abordagem do delírio abriu caminho para que Lacan, mais tarde, desenvolvesse toda uma teoria sobre o assunto em seus principais trabalhos sobre o tema da psicose: o célebre Seminário 3: as psicoses (1955-1956) e o texto "De uma questão preliminar a todo tratamento possível da psicose" (1957-1958). Ele aprofundou a pesquisa sobre a psicose, apostando na existência da transferência neste campo, o que viabiliza seu tratamento pela psicanálise. A produção delirante é, neste sentido, um meio pelo qual o psicótico procura restabelecer os laços com o mundo externo, reconstruindo a realidade. Desta forma, a psicanálise afirma que é 
fundamental escutar o discurso delirante pois aí situa-se o sujeito. Este é justamente o eixo que consideramos prioritário para refletir sobre a clínica da psicose a partir de uma experiência de trabalho na instituição de saúde mental.

\section{De que sujeito se trata em psicanálise?}

Consideramos importante, neste momento, fazer um breve histórico do conceito de sujeito na psicanálise, nascido com a inauguração do conceito de inconsciente por Freud. Tal conceito foi introduzido por Lacan a partir da referência ao sujeito cartesiano fundado no cogito cartesiano: "penso, logo sol". Lacan anuncia que o sujeito da psicanálise nasce com a ciência moderna - " o sujeito sobre quem operamos em psicanálise só pode ser o sujeito da ciência" (Lacan, 1998, p. 873). Entretanto, este sujeito é excluído pela própria ciência de seu campo de investigação. Lacan subverte o sujeito cartesiano a partir da descoberta do inconsciente por Freud. Ele demonstra que o sujeito na psicanálise não é o sujeito da razão, mas algo que surge nas falhas do discurso e nos tropeços da fala. Assim, transforma a fórmula: "penso, logo sou" em "eu não sou lá onde sou joguete de meu pensamento; penso naquilo que sou lá onde não penso pensar" (Lacan, 1998, p. 521). Neste sentido, o sujeito constitui-se a partir da falta-a-ser, ao contrário do sujeito cartesiano que se caracteriza como ancorado no ser. Para a psicanálise, o sujeito se define por sua divisão e não por uma unidade comparável ao eu.

É nesta perspectiva que, quanto ao sujeito, podemos dizer que não se trata de uma entidade, mas de algo estrutural, inscrito na linguagem, a partir da qual se pode recolher os seus efeitos. Trata-se de um sujeito marcado pela linguagem, articulado à cadeia significante, que surge no ato da fala. Na medida em que há um sujeito falante convoca-se não somente o outro imaginário, mas também e principalmente um terceiro, o grande Outro, que constitui a posição do sujeito enquanto falante. O Outro é um termo utilizado por Lacan para definir um lugar simbólico, o campo da linguagem, o tesouro dos significantes. Com essa noção, Lacan situa a questão da alteridade; o grande Outro não é o semelhante. Ele se distingue do parceiro imaginário, o pequeno outro. Foi no Seminário 2: o eu na teoria de Freud e na técnica da psicanálise (1954-1955) que Lacan introduziu pela primeira vez o termo grande Outro, distinguindo-o do pequeno outro, deixando claro que é do Outro que se trata na função da fala.

Esta indicação de Lacan é particularmente interessante para investigar o conceito de sujeito na psicose. O que observamos com frequência na fala do psicótico é a invasão do pensamento presença incessantemente absoluta e invasiva. Isso foi nomeado como automatismo mental, uma síndrome definida por Clérambault (Ferreto, 2004) que inclui um conjunto de fenômenos presentes na psicose, tais como o pensamento antecipado e o eco do pensamento. $O$ que é fundamental no automatismo mental é justamente o quanto ele é a evidência da presença invasiva do significante, dizendo respeito aos efeitos das marcas do significante na relação do sujeito com o Outro ${ }^{1}$. É precisamente este ponto que valorizamos para pensar as questões do sujeito na psicose, o que fica 
mais claro ao nos remetermos à clínica.

Podemos notar a evidência da relação invasiva entre o sujeito e o Outro ao analisar um fragmento de caso clínico, que retomamos aqui, o caso Nara² $^{2}$ (Meyer, 2008). Trata-se de uma moça que, em atendimento, confidenciou sua história. A narrativa da história de Nara evidencia uma relação especial do sujeito com a linguagem, que nos indica o seu lugar de existência no mundo, lugar marcado e determinado pelo significante invasão3. Há anos Nara sente-se invadida por um grupo de pessoas, seus vizinhos, que estão a Ihe usurpar tudo o que tem. Eles invadem sua mente e conduzem sua vida. Esse grupo demoníaco age contra ela por meio do desenvolvimento de hierarquias no abstrato. É no abstrato, explica, e não por meio da realidade concreta, que eles se comunicam com ela, invadindo não só a sua mente, mas também o seu corpo. Por telepatia, eles a fazem capaz de escutar tudo que falam e tramam. Essas falas são percebidas em seu ouvido, exercendo igualmente uma pressão sobre sua mente e é aí que se tornam insuportáveis. A nosso ver, elas evidenciam a forma como Nara se sente na relação com o Outro. O abstrato seria uma forma de nomeação do Outro.

Esta passagem ilustra bem como é sentir na pele a invasão do Outro, da própria linguagem, o que na psicose evidencia-se pela cola ao significante no que ele tem de concreto, literal. Tal condição é consequência da foraclusão do Nome-do-Pai ${ }^{4}$, significante privilegiado que tem a função de barrar o Outro, permitindo que o sujeito se proteja de uma invasão sem piedade. É desta forma que o sujeito se apresenta neste caso, completamente exposto à ação do significante, falado e boicotado através dos fenômenos elementares (alucinações auditivas) e do automatismo mental.

O que pode ser observado na clínica só tem sentido a partir do conceito de transferência que sustenta a experiência de análise, mesmo que Freud não apostasse nela no caso da psicose. A noção de transferência, dessa forma, é fundamental para refletirmos sobre qualquer aspecto que seja da ordem do sujeito, pois é a clínica que oferece espaço para que o sujeito se expresse. Quando ele fala, fala a alguém e este tem um lugar especial de escuta. Como mencionado anteriormente, Freud desenvolveu o conceito de transferência a partir da clínica da neurose, sendo por meio do tratamento das histéricas que ele se deparou com tal fenômeno, a princípio imprevisto. $O$ fenômeno surge como um obstáculo ao bom andamento do trabalho por manifestar-se, numa primeira experiência, sob a forma de um intenso interesse do paciente pelo analista, que Freud deixa claro de imediato, não se tratar da pessoa do analista, mas sim do que ele representa.

Foi nos "Estudos sobre a histeria" (1893-1895/1996) que surgiu pela primeira vez tal conceito na obra freudiana, principalmente na apresentação do Caso Anna O., caso atendido por Joseph Breuer. Como acentua Lacan, no Seminário 11 (1964/1988), foi a propósito deste caso que se descobriu a transferência. No entanto, foi a partir do caso Dora, em "Fragmento da análise de um caso de histeria" (1905[1901]/1996) e nos artigos sobre a técnica, que Freud conceituou formalmente a transferência, caracterizando-a como o motor do processo analítico, ao mesmo tempo que, em sua faceta de resistência, age no sentido de criar um obstáculo ao processo associativo que 
constitui a análise.

Diferente de Freud, Lacan inaugurou sua entrada na psicanálise justamente pela clínica da psicose, a partir do atendimento clínico, o caso "Aimée", nome fictício de Marguerite Anzieu. Este caso foi o tema de sua tese de doutorado "Da psicose paranoica em suas relações com a personalidade" (1932), na qual desenvolveu uma teoria sobre a paranoia, ainda com alguma herança da psiquiatria, mas já integrando-a aos moldes freudianos. Foi sua tese de doutorado sobre uma psicótica que o levou a fazer a experiência da psicanálise, por meio da clínica e, portanto, da relação transferencial que aí se estabeleceu.

Ao refletirmos sobre a transferência na clínica da psicose, percebemos que ela evidencia uma intensidade diferente em relação à forma como se manifesta na neurose, portanto seu manejo deve ser muito delicado. Na psicose, a transferência, apresenta-se frequentemente de forma maciça. Neste sentido, surge a pergunta: qual o lugar que o psicanalista deve assumir nesta clínica? Como ele pode, com sua escuta e seu desejo do analista, criar condições e espaço para que o sujeito apareça e possa se expressar?

Como mencionado, na psicose, o outro surge como o próprio Outro - presença incessantemente absoluta e invasora. Isso se dá como consequência da foraclusão do Nome-do-Pai, que deixa o sujeito exposto ao Outro, diferentemente do que ocorre na neurose. Nesta, o sujeito, estruturado pelo recalque, fica protegido do Outro, pois o recalque opera como uma mediação entre o eu e o Outro. Na psicose, o inconsciente encontra-se a céu aberto (Lacan, 1985), não dispõe da mediação fálica. Esse lugar de Outro absoluto, ao ser ocupado pelo psicanalista, conduz à forma mais característica da manifestação da transferência na psicose, como perseguição ou erotomania. Contudo, é fundamental que ele escape deste lugar a fim de promover uma abertura entre o sujeito e o Outro, criando possibilidades de construção de uma significação para o sujeito e abrindo espaço para que ele possa se expressar.

\section{O sujeito do inconsciente e o cidadão}

É na relação transferencial que o sujeito pode se expressar, através da escuta do analista, a qual the oferece um espaço de expressão. Na clínica da psicose ou de casos graves este espaço geralmente se situa na instituição, que se apresenta, então, como um lugar privilegiado de acolhimento desses casos. A clínica que se realiza aí tem como base a prática feita por muitos, tal como Miller (apud Di Ciaccia, 1999) a concebeu. São muitos (da equipe) que atendem muitos (pacientes) num trabalho que se pauta na escuta do que o sujeito tem a dizer, seja pela fala verbal ou por um ato corporal. Porém, nem todas as instituições são equivalentes, e a prática feita por muitos é diferente segundo o funcionamento da instituição. Como nos orienta Di Ciaccia (1999), na instituição de saúde mental que tem como referência a psicanálise, o trabalho feito por muitos tem seu fundamento no discurso analítico que é o avesso do discurso do mestre. Este, o discurso do mestre, é o discurso que, como seu bem e seu mal, se impõe de maneira a dominar naturalmente 
toda a instituição, como acontece na igreja e no exército. O discurso analítico, ao contrário, vem aqui representar a ideia de uma horizontalidade, privilegiando diversos campos de saber. Numa instituição, essa via promove a possibilidade de escuta do sujeito do inconsciente. No entanto, as diversas disciplinas não estão necessariamente atravessadas pela psicanálise, mesmo que a instituição esteja, o que dificulta muitas vezes essa escuta e a consequente leitura da expressão do sujeito.

A clínica da atenção psicossocial que inclui, como dito, a clínica do sujeito do inconsciente e do cidadão (indivíduo), por diversas vezes age no sentido de cuidar do sujeito, cuidar de seus direitos, mas, muitas vezes, sem conseguir escutar o que esse sujeito diz. Preocupa-se bastante em atender às solicitações do sujeito, esquecendo-se, entretanto, de que ele não precisa necessariamente ser atendido nesse sentido, mas sim, escutado. Cito um exemplo de uma mãe que chega a um Centro de Atenção Psicossocial infanto juvenil do município do Rio de Janeiro fazendo uma demanda em relação ao que ela identifica como direitos de seu filho "especial". Se tal demanda é atendida, perde-se uma oportunidade de saber um pouco mais sobre o sofrimento desta mãe a partir da relação com a "inadequação" apresentada por seu filho à sociedade. Foi o que aconteceu com Maíra ${ }^{5}$, que faz tratamento num CAPSi localizado no município do Rio de Janeiro. Sua mãe alega que não pode levá-la àquela instituição porque Ihe falta o dinheiro da passagem. Solicita, desta forma, um benefício. Mesmo que tal benefício seja direito dessa paciente, é importante escutar um pouco além desse pedido, antes de prontamente atendê-lo. Quando se trata do sujeito, precisamos ter calma e não nos precipitar. Muitas vezes o que ele pede não é o que ele deseja.

Não é simples estar diante de casos graves como os de psicose e de autismo e os que apresentam grande vulnerabilidade social. A equipe de profissionais, das diferentes disciplinas, necessita estar em constante trabalho de supervisão para que seja capaz de localizar suas próprias possibilidades e impossibilidades de sustentar o que o sujeito the endereça. Tal dificuldade pode ser observada através do caso de Lara ${ }^{6}$, uma adolescente de 15 anos, que chegou para atendimento no CAPSi após uma situação de tentativa de suicídio ocorrida na escola e que não se efetivou. Sua mãe conta que há dois anos ela já apresentava a escuta de vozes que a acompanham. Durante esse tempo foram encontradas algumas maneiras de lidar com elas. Uma delas, a principal, uma voz de homem, recebeu inclusive um nome. Recentemente, Lara se desorganizou. Levou chumbinho (veneno de rato) para a escola, lugar que é muito importante para ela. Esse fato culminou na abertura de uma crise que a levou ao CAPSi. Os profissionais da escola mostraram-se bastante assustados e sem saber o que fazer. O CAPSi recebeu Lara, trazida por sua mãe, que se desdobra para estar presente junto da filha nesse momento de sua vida. Lara, com a ajuda do pai, estudou muito para entrar no colégio onde estuda. Esse lugar é muito valorizado por ela. Sente-se imensamente orgulhosa por ter sido classificada num concurso tão concorrido. Não quer perder esse lugar. Mas, no momento de sua crise e nos meses seguintes, não consegue voltar para a escola. Acaba sendo reprovada e, no início do novo semestre, reinicia normalmente sua vida escolar. No 
entanto, agora que algo irrompeu e a crise se deu, Lara não tem conseguido mais estar na escola sem se sentir vulnerável.

No CAPSi, alguns profissionais ficaram responsáveis por atendê-la e à sua família. Em grupo, ela não consegue falar do que lhe atormenta. No caso dela, foi importante construir um espaço de atendimento individual. No entanto, esbarramos, no momento, com uma dificuldade: quem vai escutar Lara? Quem de fato vai tomar o caso e se colocar disponível para acolher seu discurso, o discurso delirante? Todos dizem conversar com ela, mas enfatizam que ela não tem falado das vozes; quem conta sobre as vozes é a mãe. O que podemos constatar é que Lara não tem um lugar onde se sinta à vontade para falar de algo tão particular, tão íntimo. Mas, será que esse lugar existe de antemão ou deve ser construído a partir do desejo de escuta de um profissional? Constatamos aí como tal equipe recua, mesmo sem se dar conta, desse lugar de quem está disponível para acolher e receber o discurso delirante. Como lidar com isso? Tomemos aqui como referência a orientação de Lacan de que não podemos recuar quando estamos diante da psicose, ou seja, diante da diferença.

Podemos pensar, como já desenvolvemos em outra ocasião (Meyer, 2006) que esse lugar nasce a partir do desejo do analista, no caso aqui exposto, do clínico, ou seja, de quem se coloque no lugar de escuta. Tal desejo diz respeito ao desejo de escuta, de acolher o delírio, o discurso do sujeito; é o desejo de que haja trabalho analítico. No caso da psicose, partimos do pressuposto de que é o desejo do analista investido de uma condição especial, ou seja, de uma certa disponibilidade para a clínica da psicose, que pode viabilizar a transferência. Trata-se de uma aposta de que o sujeito, ao se endereçar a alguém que possa escutá-lo, pode construir algum sentido que faça as vezes de amarração, de estabilização para ele. Lara só vai falar das vozes quando alguém que se coloque nesse lugar de escuta se disponibilizar para ela. E essa possibilidade precisa ser construída a partir de um trabalho de supervisão clínica e institucional em equipe, o que se torna possível na relação transferencial.

\section{Conclusão}

Neste momento de encerramento, não se trata de fechar conclusões, mas de abrir novos caminhos a partir do que foi desenvolvido. Neste sentido, é fundamental fazer uma articulação entre o desejo do analista e a função de secretário que o psicanalista assume ou não em cada caso de psicose e quais as consequências clínicas que daí decorrem (Meyer, 2006). Lacan (1955-1956) define a noção de secretário no seminário sobre as psicoses, indicando com precisão um lugar para o psicanalista na clínica da psicose, como lugar de escuta e de valorização do discurso do sujeito, fundamental para que alguma forma de tratamento se efetive. Ser secretário do alienado significa colocar-se disponível para incluir como eixo de sua função o saber que o psicótico traz em sua estrutura. Trata-se de uma estrutura que apresenta um saber sobre o inconsciente, sobre o não sabido por todos nós. Este saber coloca-o numa posição de refém do próprio inconsciente, do Outro que o invade e ordena. É uma estrutura que se organiza nestas bases, como indica Lacan nesse 
mesmo seminário, sobre um tamborete de três pés que a qualquer momento pode não aguentar a pressão do saber que the concerne.

Para assumir a função de secretário é preciso haver desejo do analista, pois é o que sustenta a transferência na clínica da psicose, no sentido de valorizar o saber do sujeito e os caminhos que ele indica. Para tanto, é preciso assumir um lugar de não-saber, que significa despir-se de seus conceitos e preconceitos, como condição para acolher um saber sobre a diferença, saber este na maioria das vezes não compartilhado socialmente. É isto que pode levar o sujeito a incluir o psicanalista (ou qualquer profissional que assuma a função de escuta do sujeito) em seu mundo, permitindo a sua presença, a sua escuta, o seu acompanhamento. A psicanálise, ao supor esse saber ao sujeito, vai na contramão de toda a abordagem da chamada "loucura" que destitui o sujeito de qualquer saber.

Uma instituição pode constituir-se como um lugar privilegiado para o tratamento da psicose quando consegue criar espaços diferenciados de acolhimento e de escuta do discurso do psicótico. Quanto mais espaços de acolhimento e de escuta, mais possibilidades de o discurso se endereçar e encontrar um destinatário. Isso parece simples, até óbvio, mas não é. Quem trabalha com psicóticos sabe o quanto é custosa a possibilidade da fala se endereçar, principalmente porque o destinatário precisa estar muito disponível e essa disponibilidade não é um ato voluntário e sim inconsciente tem relação com o desejo daquele que ocupa o lugar de analista de sustentar eticamente o desejo do analista.

A relação da psicanálise com a instituição, como desenvolvemos ao longo deste artigo, tornase possível na medida que manejamos e articulamos a clínica do sujeito e a clínica da atenção psicossocial, o que traz uma riqueza tanto para o campo da psicanálise, quanto para o campo da saúde mental. É a partir da articulação dessas duas clínicas que apostamos na escuta do sujeito e na valorização do cidadão.

\section{Notas:}

1 É importante deixar claro que essa é uma leitura psicanalítica do automatismo mental.

${ }^{2}$ Nome fictício. Este caso foi trabalhado por ocasião do atendimento no CAPS Clarice Lispector e foi relatado e analisado em Meyer, G. R. (2008). Algumas considerações sobre o sujeito na psicose. Revista Ágora - Estudos em Teoria Psicanalítica. Rio de Janeiro: Contracapa.

${ }^{3} \mathrm{O}$ que aparece em itálico refere-se à fala de Nara.

${ }^{4}$ Para melhor compreender esse mecanismo ver Lacan, J. (1999). O seminário, livro 5: as formações do inconsciente. Rio de Janeiro: Jorge Zahar (Trabalho original publicado em 1957-1958).

${ }^{5}$ Nome fictício.

${ }^{6}$ Nome fictício.

\section{Referências Bibliográficas}


Di Ciaccia, A. (1999). Da fundação por um à prática feita por muitos. Revista Curinga - Psicanálise e Saúde mental, (13). Belo Horizonte: Escola Brasileira de Psicanálise.

Freud, S. (1996). Fragmento da análise de um caso de histeria. In J. Salomão (Trad.) Edição Standard Brasileira das obras psicológicas completas de Sigmund Freud (Vol. 7). Rio de Janeiro: Imago (Trabalho original publicado em 1905[1901]).

Freud, S. (1996). Notas psicanalíticas sobre um relato autobiográfico de um caso de paranoia - caso Schreber. In J. Salomão (Trad.) Edição Standard Brasileira das obras psicológicas completas de Sigmund Freud (Vol. 12). Rio de Janeiro: Imago (Trabalho original publicado em 1911).

Freud, S. (1996). Recomendações aos médicos que exercem a psicanálise. In J. Salomão (Trad.) Edição Standard Brasileira das obras psicológicas completas de Sigmund Freud (Vol. 12). Rio de Janeiro: Imago (Trabalho original publicado em 1912).

Freud, S. (1996). Linhas de progresso na terapia psicanalítica. In J. Salomão (Trad.) Edição Standard Brasileira das obras psicológicas completas de Sigmund Freud (Vol. 17). Rio de Janeiro: Imago (Trabalho original publicado em 1918).

Ferreto, J. (2004). O automatismo mental. Revista Tempo Freudiano - A clínica da psicose: Lacan e a psiquiatria. Rio de Janeiro: Tempo Freudiano Associação Psicanalítica.

Lacan, J. (1998). A instância da letra no inconsciente ou a razão desde Freud. Escritos. Rio de Janeiro: Jorge Zahar (Trabalho original publicado em 1957).

Lacan, J. (1998). De uma questão preliminar a todo tratamento possível da psicose. Escritos. Rio de Janeiro: Jorge Zahar (Trabalho original publicado em 1957-1958).

Lacan, J. (1998). Subversão do sujeito e dialética do desejo no inconsciente freudiano. Escritos. Rio de Janeiro: Jorge Zahar (Trabalho original publicado em 1960).

Lacan, J. (1998). A ciência e a verdade. Escritos. Rio de Janeiro: Jorge Zahar (Trabalho original publicado em 1966).

Lacan, J. (1985). O seminário, livro 2: o eu na teoria de Freud e na técnica da psicanálise. Rio de Janeiro: Jorge Zahar (Trabalho original publicado em 1954-1955).

Lacan, J. (1985). O seminário, livro 3: as psicoses. Rio de Janeiro: Jorge Zahar (Trabalho original publicado em 1955-1956).

Lacan, J. (1986). O seminário, livro 7: a ética da psicanálise. Rio de Janeiro: Jorge Zahar (Trabalho original publicado em 1959-1960).

Lacan, J. (1988). O seminário, livro 11: os quatro conceitos fundamentais da psicanálise. Rio de Janeiro: Jorge Zahar (Trabalho original publicado em 1964).

Lacan, J. (1999). O seminário, livro 5: as formações do inconsciente. Rio de Janeiro: Jorge Zahar (Trabalho original publicado em 1957-1958).

Lacan, J. (1987). Da psicose paranoica em suas relações com a personalidade. Rio de Janeiro: Forense Universitária (Trabalho original publicado em 1932).

Meyer, G. R. (2006). A clínica da psicose: transferência e desejo do analista. (Tese de doutorado). 
Curso de Pós-graduação em Psicologia Clínica, Universidade de São Paulo.

Meyer, G. R. (2008). Algumas considerações sobre o sujeito na psicose. Revista Ágora - Estudos em Teoria Psicanalítica. Rio de Janeiro: Contracapa.

Zenoni, A. (2000). Psicanálise e Instituição. Abrecampos - Revista de Saúde Mental do Instituto Raul Soares, 1(0). Belo Horizonte: Rede FHEMIG.

Ministério da Saúde. Secretaria da Atenção à Saúde - Política Nacional de Humanização da Atenção e Gestão do SUS, 2009.

Citacão/Citation: Meyer, G. R. (mai. a out. 2016). A psicanálise na instituição de saúde mental. Revista aSEPHallus de Orientação Lacaniana, 11(22), 108-121. Disponível em www.isepol.com/asephallus. doi: 10.17852/1809-709x.2019v11n22p108-121.

Editor do artigo: Tania Coelho dos Santos.

Recebido/Received: 24/05/2016 / 05/24/2016.

Aceito/Accepted: 10/06/2016 / 06/10/2016.

Copyright: (c) 2013 Associação Núcleo Sephora de Pesquisa sobre o moderno e o contemporâneo. Este é um artigo de livre acesso, que permite uso irrestrito, distribuição e reprodução em qualquer meio, desde que o autor e a fonte sejam citados/This is an open-access article, which permites unrestricted use, distribution, and reproduction in any medium, provided the author and source are credited. 